\title{
Aa. Vv., Études Rabelaisiennes
}

\section{Michele Mastroianni}

\section{(2) OpenEdition}

\section{Journals}

\section{Edizione digitale}

URL: http://journals.openedition.org/studifrancesi/7865

DOI: $10.4000 /$ studifrancesi.7865

ISSN: 2421-5856

\section{Editore}

Rosenberg \& Sellier

\section{Edizione cartacea}

Data di pubblicazione: 1 juillet 2009

Paginazione: 379

ISSN: 0039-2944

\section{Notizia bibliografica digitale}

Michele Mastroianni, «Aa. Vv., Études Rabelaisiennes», Studi Francesi [Online], 158 (LIII | II) | 2009, online dal 30 novembre 2015, consultato il 13 janvier 2021. URL: http://journals.openedition.org/ studifrancesi/7865 ; DOI: https://doi.org/10.4000/studifrancesi.7865

Questo documento è stato generato automaticamente il 13 janvier 2021.

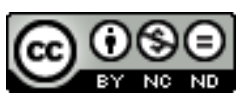

Studi Francesi è distribuita con Licenza Creative Commons Attribuzione - Non commerciale - Non opere derivate 4.0 Internazionale. 


\title{
Aa. Vv., Études Rabelaisiennes
}

\author{
Michele Mastroianni
}

\section{NOTIZIA}

Études Rabelaisiennes, tome XLVI, Genève, Droz, 2008 («Travaux d'Humanisme et Renaissance», n CDXXXVII), pp. 137.

1 Nel primo dei cinque studi qui raccolti Jan MIERNOWSKI (La poétique du massacre de Rabelais à Racine, pp. 7-36), ripercorrendo i due secoli che vanno da Rabelais a Racine secoli storicamente caratterizzati da una successione di massacri connessi quasi sempre a guerre di religione o a interventi statali giustificati da una politica 'religiosa' -, evidenzia i nessi tra questa situazione e i riflessi che essa ha in letteratura ove il tema del massacro, da Rabelais a d'Aubigné, da Ronsard ai tragici cinque e secenteschi, si configura lungo direttive tracciate da una vera e propria poetica, seguendo un itinerario che va da un'epoca in cui il massacro è un mito letterario a un'epoca in cui esso è un avvenimento fondatore di un ordine politico nuovo. Emmanuelle LACORE MARTIN (Les marginalia du volume BNF RES- G-2108 (1) et (2), pp. 37-75) indaga su di un volume della BN parigina che contiene sotto una stessa rilegatura due opere distinte: $i$ Liber de Mensibus Atticis di Teodoro di Gaza e il De annis et mensibus, caeterisque temporum partibus di Lilio Gregorio Giraldi. Ora, il frontespizio dell'opera di Teodoro reca l'ex-libris di Rabelais e il trattato di Giraldi contiene delle annotazioni marginali che a Rabelais sono attribuite. L'A. studia sia la composizione del volume sia le annotazioni, riconoscendo la presenza di almeno due mani e sottolineando una differenza di stile fra le glosse del primo e quelle del secondo annotatore, pur confermando che in uno dei due casi siamo realmente in presenza di interventi di Rabelais. Alexandre DICKOW («Remede contre fascherie?» Critique de l"apatheia" dans le "Tiers Livre de Pantagruel”, pp. 77-99), partendo dai versi dedicatori del Tiers Livre in cui Rabelais esorta Marguerite de Navarre ad abbandonare la sua divina Apathie e ripercorrendo questo terzo volume dell'opera rabelaisiana insieme al Quart Livre, delinea l'evoluzione del carattere di Pantagruel nella prospettiva, appunto, del ruolo dell'apatheia e della critica che le viene mossa, per cui vediamo il gigante perdere progressivamente la sua impassibilità di 
saggio e manifestarsi sempre più sensibile alle emozioni. E. Bruce HAYES (A Decade of Silence: Rabelais's Return to Writing in a More Dangerous World, pp. 101-113), rivolgendo la sua attenzione al Tiers Livre, si interroga sulle motivazioni del return to writing di Rabelais dopo dieci anni di silenzio e sulle differenze di prospettiva che ritroviamo nella nuova opera rispetto alle due precedenti, differenze che vengono riportate al tormentato periodo storico susseguente l'affaire des placards, come testimoniano anche, per quanto concerne una situazione inquieta e instabile, i testi liminari che vengono puntualmente analizzati. Nicolas LE CADET (Les rééditions de la "Pantagrueline Prognostication" et le tissage énonciatif chez Rabelais, pp. 115-136) studia le varianti delle edizioni della Pantagrueline Prognostication (12 edizioni fra il 1532 e il 1548, di cui cinque vengono analizzate nel presente studio) convinto che «un'analisi diacronica non debba accontentarsi di una prospettiva editoriale, grammaticale, materiale o lessicale, in quanto molte trasformazioni dell'opuscolo si chiariscono se si proietta su di loro una prospettiva enunciativa». Infatti, Rabelais avrebbe, da un'edizione all'altra, «ristrutturato il dispositivo enunciativo per rispondere a un doppio obiettivo: da una parte, appropriarsi del genere tradizionale delle pronosticazioni gioiose contemporanee; dall'altra, collegare strettamente l'opuscolo alle due opere romanzesche già pubblicate». 